\title{
PERFORMANCE EVALUATION OF ENERGY EFFICIENT CLUSTERING PROTOCOL FOR CLUSTER HEAD SELECTION IN WIRELESS SENSOR NETWORK
}

\author{
Harpreet Kaur $^{1}$ and Prof Ameeta Seehra ${ }^{2}$ \\ ${ }^{1}$ Department of Electronics and Communication Engineering, GNDEC, Ludhiana, India \\ ${ }^{2}$ Department of Electronics and Communication Engineering, GNDEC, Ludhiana, India
}

\begin{abstract}
Wireless sensor network are emerging in various fields like environmental monitoring, mining, surveillance system, medical monitoring. LEACH protocol is one of the predominantly used clustering routing protocols in wireless sensor networks. In Leach each node has equal chance to become a cluster head which make the energy dissipated of each node be moderately balanced. We have pioneered an improved algorithm named as Novel Leach based on Leach protocol. The proposed algorithm shows the significant improvement in network lifetime. Comparison of proposed algorithm is done with basic leach in terms of network life time, cluster head selection, energy consumption, and data transmission to base station. The simulation results shows that proposed algorithm can reduce network energy consumption and prolong network life commendably. Simulation of our protocol is done with Matlab.
\end{abstract}

\section{Keywords}

Wireless sensor network, Leach, Leach C, Leach CC, Cluster Head Selection, Network life time, residual energy.

\section{INTRODUCTION}

Wireless Sensor Networks are usually self-organized wireless ad hoc networks comprising of a large number of resource constrained sensor nodes. The vital role of these sensors nodes is systematic collection of data. After that sensor nodes transmit aggregated data to BS. Wireless sensor network has spacious application in military recce, medical assistance, agriculture, environmental monitoring and other infomercial areas. Wireless Sensor Network [1] produce large number of data which is aggregated at numerous levels. A multidimensional aggregation approach [13] is considered for exhibiting the node parameters for each network. The performance of sensor network is determined by memory, battery power, bandwidth etc.

Life span of sensor network is an important parameter for efficient design of data aggregating schemes in sensor network. Energy organization plays important role in the deployment of sensor networks. The available energy is considered a major factor when designing protocols in a sensor network. Hence existing energy plays important role in designing of protocol in wireless sensor network.Low-Energy Adaptive Clustering Hierarchy (LEACH) is a clustering routing algorithm in WSN.In LEACH cluster head is determined randomely,it is not based on remaining energy of 
sensor nodes and which results that less energy nodes come to an end of energy in advance. It decrease in life time of sensor network. Our research analysis the significance of Leach protocol in cluster head selection and energy saving of sensor network.

\section{INTRODUCTION TO LEACH PROTOCOL}

W. R Heinzelman proposed LEACH protocol, which based on cluster structure and hierarchical technology. Relative to the traditional protocol, LEACH could save a greater degree of energy. LEACH is the most commonly used clustering algorithm in wireless sensor network .In LEACH, the nodes are deployed in specific area and organized into clusters. The communication process is divided into rounds. Each round having two phases namely set-up and steady-state phases. Each cluster has a cluster head which is accountable for creating a TDMA (time division multiple access) table. It intimate its member sensor nodes when to get transmit data packets The main function of cluster head is to collect data which is coming from different sensor member nodes and transmit data packets to BS.Cluster head serve as a relay node to provide assistance to senor nodes to shorten the transmission distance also it saves energy.

\subsection{Setup Phase}

Each node in the monitoring field decides self-governing of other sensor nodes whether selected node can be cluster head in current round .In this phase, each sensor node generate a random number between 0 and 1.If the number is larger than threshold value then node become a cluster head for current round and send availability message to its neighboring sensor nodes. In the setup phase, the node becomes a cluster head with a probability $P$. and send its data packets. On the other side, the regular nodes choose their cluster-head based on the least communication energy to reach the cluster-head. The threshold is set as

$$
T(n)=\left\{\begin{array}{cl}
\frac{p}{1-p *\left(r \bmod \frac{1}{p}\right)} & \text { if } n \in \mathrm{G} \\
0 & \text { if } n \notin \mathrm{G}
\end{array}\right.
$$

Where $P$ denotes the percentage of cluster head, $r$ denotes the current round and $G$ denotes as set of nodes that are not become cluster heads. According to this threshold value, each node in the sensor network have chance to become a cluster head at 1/P round. When the first round occur each node has probability to become a cluster head and the nodes which are chosen to become cluster head in first round, they can't participate for cluster head selection in next round Once the cluster-heads have been chosen, the cluster-heads use CSMA MAC protocol to broadcast advertisement messages to the remaining sensor nodes. The regular nodes must keep their receivers on during this phase to hear the advertisements of all the cluster-heads. After this phase, each regular node decides which cluster to join for the current round. The other sensor node will inform the cluster-head that it will become a member of the cluster. Each regular node transmits this information back to the cluster-head again using a CSMA MAC protocol. The cluster-head receives all the messages for sensor nodes and would interested to intersect the clusters. Based on the number of regular nodes in the cluster, the cluster-head creates a TDMA schedule telling each regular node when it can transmit. This schedule is broadcast back to the regular nodes in the cluster. 


\subsection{Steady State Phase}

The cluster head selection in each cluster during the setup phase ensures the data transmission in steady state phase when there is need to transmit data, first they will send data to Ch. during idle slot canned in TDMA schedule table. Cluster heads should maintain communication status at all times and it will help to receive data from different sensor nodes. After receiving all the data sent by their members, CHs will aggregate them firstly and then send them to BS. When some sensor nodes may detect similar data them data reduce unwanted bandwidth cost, energy consumption is less. To overcome the problem of Cluster head dies early, a new round starts and new clusters formation will be done in the sensor network.

\section{SYSTEM MODEL}

\subsection{A Radio Energy Model}

We consider a wireless sensor network which consist of 100 sensor nodes, area used is $100 \times 100$ square meters.

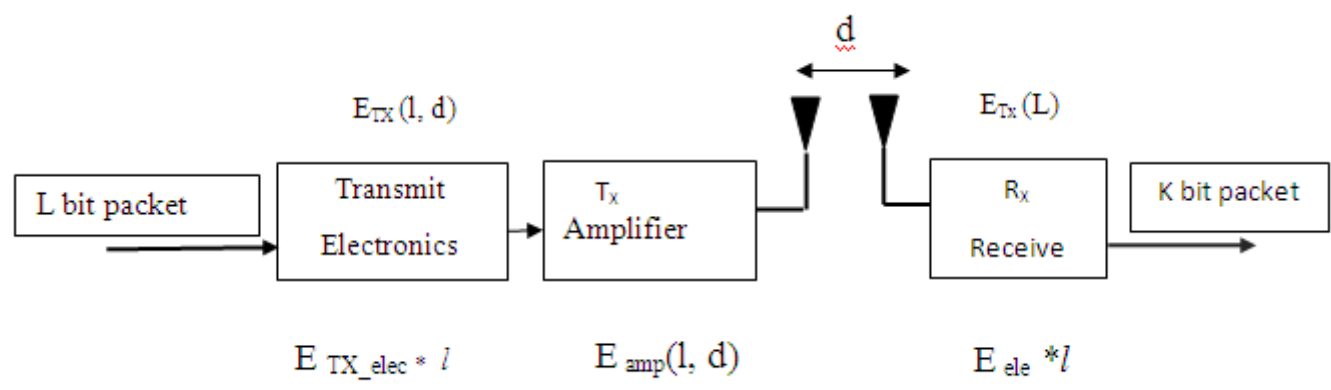

Figure 1 Radio energy model

We use a simplified model shown in figure 1 for the communication energy dissipation. In accordance with the distance between the source node and the destination node, we used the free space ( $\mathrm{d}^{2}$ power loss) and the multi-path fading ( $\mathrm{d}^{4}$ power loss) channel models. Thus, the energy spent for transmission of an l-bit packet over distanced $d$ is:

$$
\begin{aligned}
& \mathbf{E}_{\mathbf{T X}}(\boldsymbol{l}, \boldsymbol{d})=\mathrm{E}_{\mathrm{TX} \_ \text {elec }} * l+\mathrm{E}_{\text {amp }}(d) * l \\
& \mathbf{E}_{\mathbf{T X}}(\boldsymbol{l}, \boldsymbol{d})=\begin{array}{rl}
\mathrm{L} \mathrm{E}_{\text {elec }}+l \varepsilon_{F S} * \mathrm{~d}^{2} & \mathrm{~d}<\mathrm{d}_{\text {crossover }} \\
\mathrm{L} \mathrm{E}_{\text {elec }}+l \varepsilon_{T R} * \mathrm{~d}^{4} & \mathrm{~d} \geq \mathrm{d}_{\mathrm{o}}
\end{array}
\end{aligned}
$$

Eelec is the energy being dissipated to run the transmitter or receiver circuitry. The parameters $\varepsilon_{\text {TR }}$ and $\varepsilon_{\mathbf{F S}}$ is the amount of energy dissipates per bit in the radio frequency amplifier according to the crossover distance $\mathrm{d}_{0}$, 


$$
\text { do }=\sqrt{\frac{\varepsilon_{f s}}{\varepsilon_{\mathrm{t} r}}}
$$

to receive $l$ message bit, the radio apply energy

$$
\operatorname{ERX}(l)=\text { ERX_elec }(1)=l \text { E elec }
$$

\subsection{Optimal Clustering}

In WSN the optimal probability of any node to become a cluster head is very important. In optimal clustering energy consumption is properly distributed along with all sensor nodes In this radio model area is assumed $\mathrm{A}=\mathrm{M} \mathrm{X} \mathrm{M}$ square meter. Let there be $\mathrm{n}$ Nodes are randomly distributed .Assume that base station is located on fix place.

If there are $\mathrm{K}$ cluster in sensor network, then average node per cluster is noticed as $\mathrm{n} / \mathrm{k}$.. So there will be one cluster head and remaining $(\mathrm{n} / \mathrm{k}-1)$ are non-cluster head nodes.

$. \mathrm{E}_{\mathrm{NON} \_} \mathrm{ch}=\mathrm{L} . \mathrm{E}_{\mathrm{ELEC}}+\mathrm{E}_{\mathrm{AMP}}(\mathrm{L}, \mathrm{d})$

Now energy dissipated by cluster head is given by

$\mathrm{E}_{\mathrm{CH}}=\mathrm{L} \mathrm{E}_{\mathrm{ELEC}}(\mathrm{n} / \mathrm{k}-1)+\mathrm{L} \mathrm{E}_{\mathrm{DA}} \mathrm{n} / \mathrm{k}+\mathrm{L} \mathrm{E} \mathrm{E}_{\mathrm{ELCC}}+\mathrm{L} \mathrm{E}_{\mathrm{AMP}} \mathrm{d}^{4}$ to BS

Where $\mathrm{k}$ is the number of Cluster, $\mathrm{E}_{\mathrm{DA}}$ is the data aggregation and $\mathrm{d}_{\mathrm{to}} \mathrm{BS}$ is the average distance between a $\mathrm{CH}$ and $\mathrm{BS}$ which is given by

$$
\mathrm{d}_{\mathrm{BS}}^{2}=\int \sqrt{x^{2}+y^{2}} \times \frac{1}{A} \quad=0.765 \times \frac{M}{2}
$$

Hence, energy dissipated by a non $\mathrm{CH}$ node is given by

$\mathrm{E}_{\mathrm{NON} \mathrm{CH}}=\mathrm{L} \times\left(\mathrm{E}_{\mathrm{ELEC}}+\mathcal{E}_{\mathrm{FS}} \mathrm{X} \mathrm{d} \mathrm{C}_{\mathrm{CH}}^{2}\right)$

Where $\mathrm{d}_{\mathrm{CH}}$ is the average distance between a non $\mathrm{CH}$ node and its associated $\mathrm{CH}$, which is given by equation

$$
\mathrm{d}_{\mathrm{CH}}^{2}=\iint\left(\mathrm{x}^{2}+\mathrm{y}^{2}\right) \mathrm{x} \rho(x, y) d x d y={\frac{M^{2}}{2 \pi k}}^{2}
$$

Where $\rho(x, y)$ is the node distribution and $\mathrm{M}$ is the area of monitoring field.

Now, the total energy dissipated is

$\mathrm{E}_{\mathrm{T}}=\mathrm{E}_{\mathrm{CH}}+\mathrm{E}_{\mathrm{NONCH}}$

Now,

$$
\mathrm{E}_{\mathrm{T}}=\mathrm{L} \times\left(2 \mathrm{n} \times \mathrm{E}_{\mathrm{ELEC}}+\mathrm{n} \times \mathrm{E}_{\mathrm{DA}}+\mathcal{E}_{\mathrm{FS}} \times\left(\mathrm{k} \times \mathrm{d}_{\text {to BS }}^{2}+\mathrm{n} \times \frac{M}{2 \pi k}^{2}\right)\right.
$$


Now we can find the minimum no of cluster by setting the derivative of $\mathrm{E}_{\mathrm{T}}$ with respect to 0

Kopt $=\sqrt{\frac{n}{2 \pi}} \times \sqrt{\frac{\varepsilon_{f s}}{\varepsilon_{m p}}} \times \frac{M}{d_{b s}^{2}}$

Average energy is estimated as

$\mathrm{E}_{\text {average }}=\frac{1}{N} \times E_{T} \times\left(1-\frac{r}{R}\right)$

Where $\mathrm{R}$ denotes the total rounds of network lifetime whereas $\mathrm{r}$ denotes the round of sensor network.

\section{SIMULATION ANALYSIS}

To evaluate the performance our proposed protocol we use matlab .

\subsection{Network Model}

1. The Base station is immovable at far away from the sensor nodes

2. The sensor nodes are homogeneous and energy constrained with even energy.

3. The energy rate for transmitting a data packet depends on the distance of transmission.

4. The communication channel is symmetric.

\section{2 .Parameters For Simulation}

We simulate leach, leach c, leach cc, proposed algorithm for wireless sensor network. The basic parameters are listed in Table 1.

Table 1 Summary of the parameters

\begin{tabular}{|l|l|l|}
\hline S.NO & PARAMETERS & VALUE \\
\hline 1 & No of Nodes & 100 \\
\hline 2 & Network Size & $(100 \times 100) \mathrm{m}^{2}$ \\
\hline 3 & Initial Energy(Eo) & $2 \mathrm{~J}$ \\
\hline 4 & Energy for Transmission (ETX) & $50 \mathrm{~nJ} / \mathrm{bit}$ \\
\hline 5 & For Energy Reception (ERX) & $50 \mathrm{~nJ} / \mathrm{bit}$ \\
\hline 6 & Free Space Energy Loss $(\mathrm{Efs})$ & $10 \mathrm{pJ} / \mathrm{bit} / \mathrm{m}^{2}$ \\
\hline 7 & Multi path Energy Loss $(\mathrm{Emp})$ & $0.0013 \mathrm{pJ} / \mathrm{bit} / \mathrm{m}^{4}$ \\
\hline 8 & Maximum no. of Rounds (rmax) & 700 \\
\hline 9 & Location of BS(Sink) & $(50,175)$ \\
\hline 10 & Adaptive Energy(E $\left.\mathrm{E}_{\mathrm{DA}}\right)$ & $5 \mathrm{n} \mathrm{J} / \mathrm{bit}$ \\
\hline
\end{tabular}




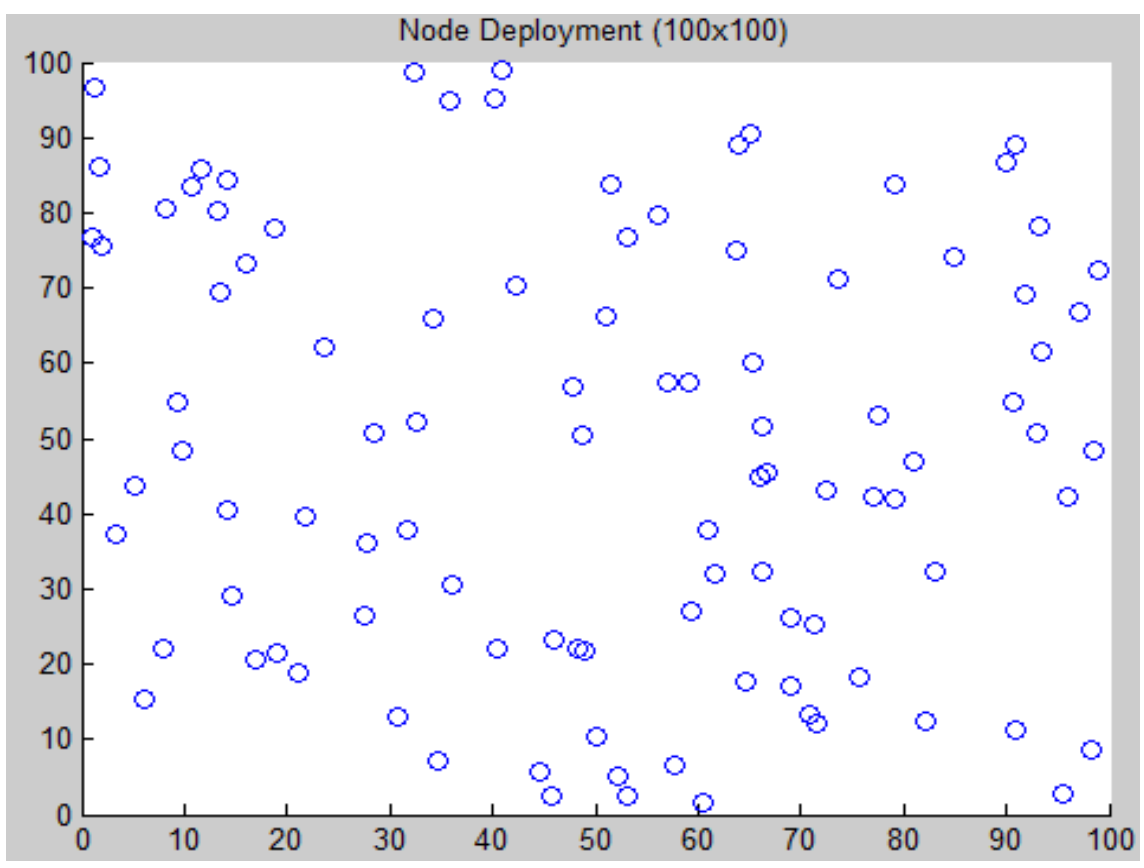

Figure 2 Node deployment of sensor nodes

Figure shows the deployment of sensor nodes. All nodes are deployed randomly in the area of 100x 100 meter square. Base station is located at $(50,175)$.

\section{FUZZY LOGIC CONTROL}

In Fuzzy inference system, the rules are generated based on input variable and output variable, called as linguistic variable, Rules are simply based on IF-THEN technique. The IF part of fuzzy rule is called antecedent and THEN part is known as consequent .Fuzzy implication operators are AND, OR etc. The combined truth of the predicate is determined by implication rules such as MIN-MAX ( Zadeh) and bounded arithmetic sum.

In FIS, there are four important steps as shown below:

1. Fuzzification: It convert the system inputs which are crisp values into fuzzy sets.

2. Rule evaluation: It fuzzified inputs variables and evaluate them to the antecedents of the fuzzy rules.

3. Aggregate conclusions: It conclude the outputs of all rules.

4. Defuzzication: It convert the fuzzy set obtained by the inference system into a single crisp value.

The input and output variable used in our work as stated as below; 
International Journal of Peer to Peer Networks (IJP2P) Vol.5, No.3, August 2014

1. Node Energy: It shows the energy level available in each node, designated by the fuzzy variable energy. Linguistic values are low, medium, high.

2. Distance to BS: It is the distance between node and base station. The linguistic variable for Distance to BS is far,medium ,close.

3. Chance: it is the chance to become a cluster head .The linguistic variable are used are very weak, low weak, weak ,low medium, high medium, medium, low strong, strong, very strong.

The linguistic variable used to represent the node energy and distance are divided into three levels high,medium,low for energy as in figure 3; and close ,medium ,far for distance to BS as in figure 4.The output of node to become a cluster head is represented by chance is divided into nine levels are very weak, low weak, weak ,low medium, high medium, medium, low strong, strong, very strong.

We have used $3^{2}=9$ rules for fuzzy base rule. The membership function developed and their corresponding linguistic states are shown in following figures.

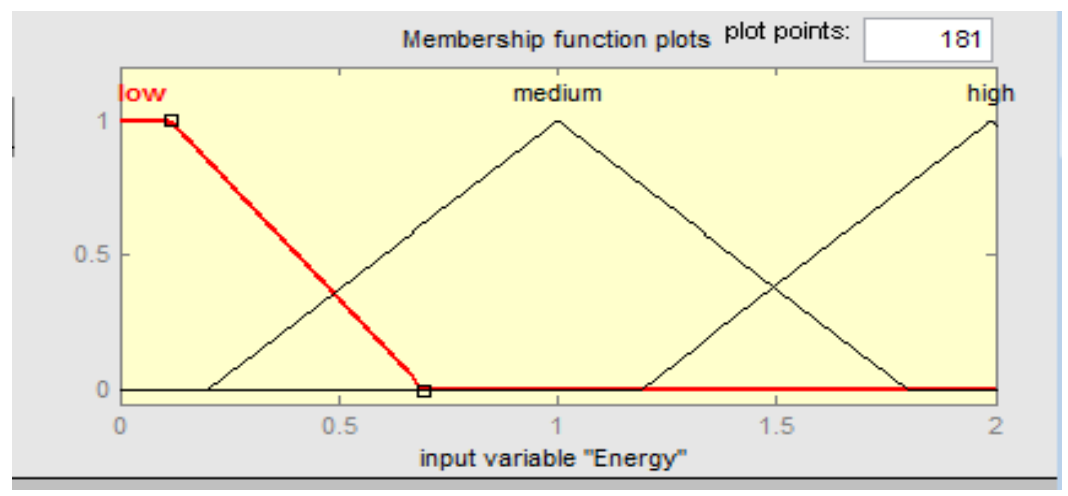

Figure 3 Membership function plot for Energy

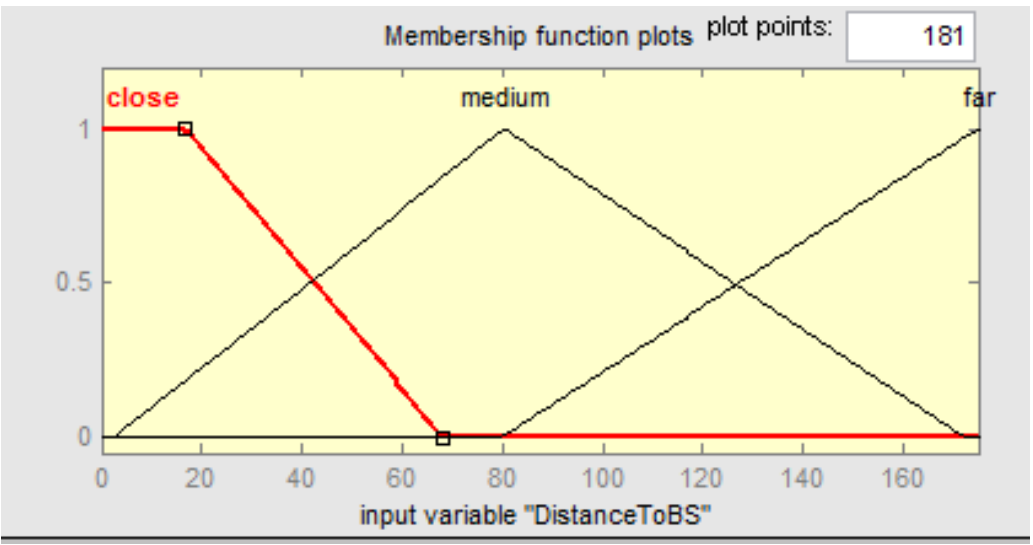

Figure 4 Membership function plot for Distance to BS 
International Journal of Peer to Peer Networks (IJP2P) Vol.5, No.3, August 2014

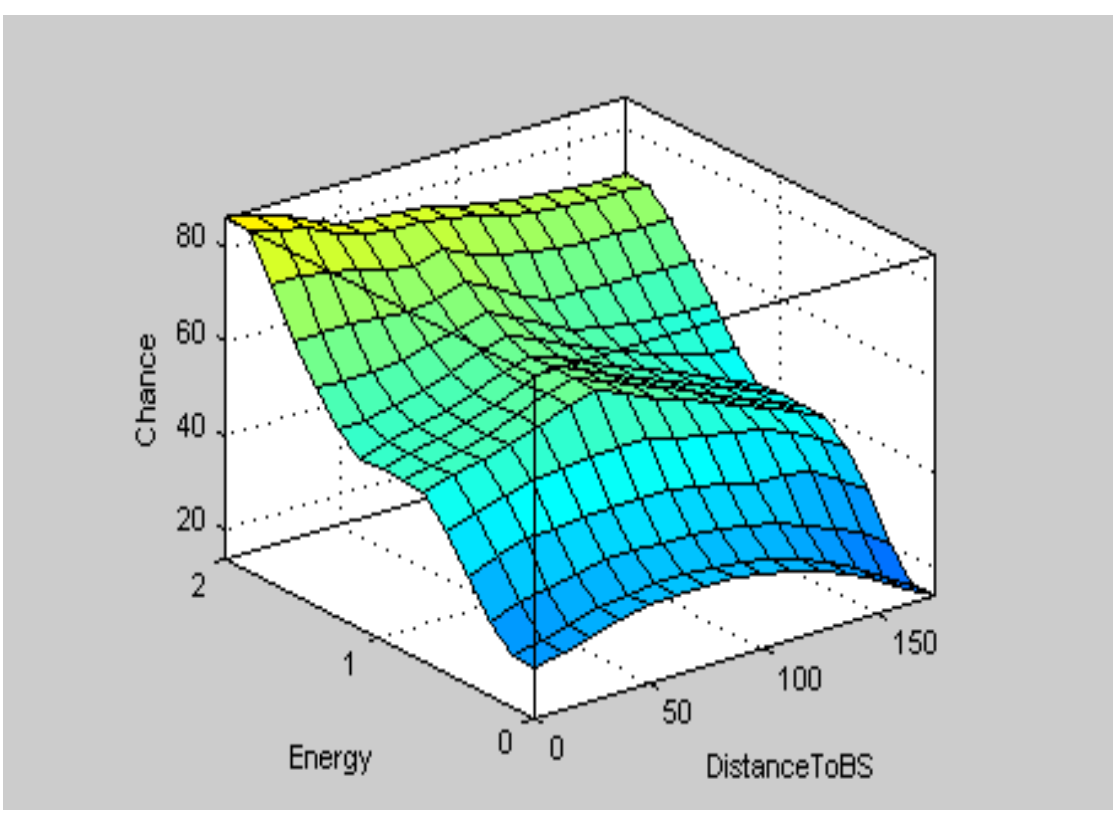

Figure 5 Surface diagram of Energy, Distance to BS, chance

TABLE 2. FUZZY RULES

\begin{tabular}{|l|l|l|l|}
\hline S.NO & ENERGY & DISTANCE TO BS & CHANCE \\
\hline 1. & LOW & FAR & V WEAK \\
\hline 2. & LOW & MEDIUM & L WEAK \\
\hline 3. & LOW & CLOSE & WEAK \\
\hline 4. & MEDIUM & FAR & L MEDIUM \\
\hline 5. & MEDIUM & MEDIUM & H MEDIUM \\
\hline 6. & MEDIUM & CLOSE & MEDIUM \\
\hline 7. & HIGH & FAR & L STRONG \\
\hline 8. & HIGH & MEDIUM & STRONG \\
\hline 9. & HIGH & CLOSE & V STRONG \\
\hline
\end{tabular}




\section{RESULTS AND DISCUSSIONS}

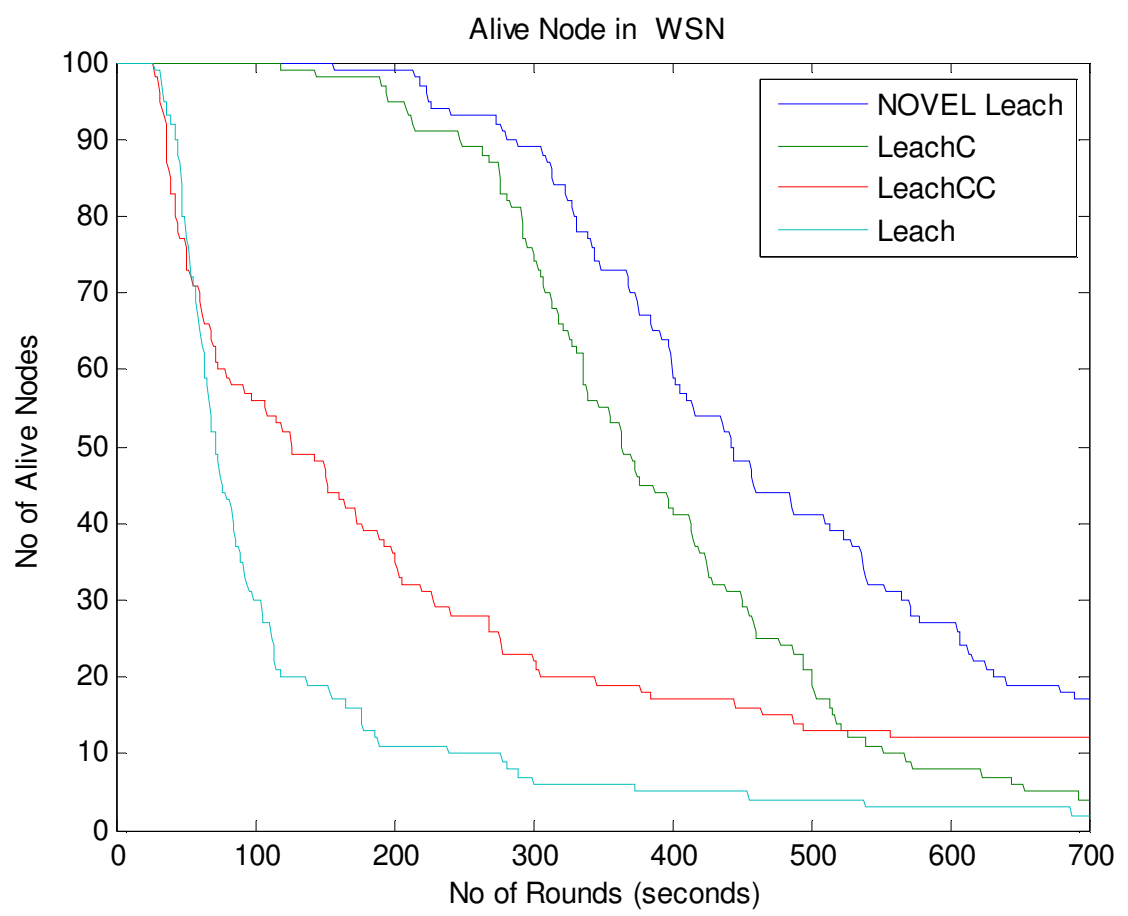

Figure 6. Comparative analysis of alive node

Table 3. Simulation results shows the no of alive node.

\begin{tabular}{|l|l|l|l|l|l|}
\hline SNO & ALGORITHM & $\begin{array}{l}\text { First node } \\
\text { dead }\end{array}$ & HND & $\begin{array}{l}\text { \% Improvement } \\
\text { FND }\end{array}$ & $\begin{array}{l}\text { \% Improvement } \\
\text { HND }\end{array}$ \\
\hline 1. & LEACH & 28 & 43 & 460.7 & 553.4 \\
\hline 2. & LEACH C & 148 & 259 & 6.08 & 8.49 \\
\hline 3. & LEACH CC & 28 & 37 & 460.7 & 659.45 \\
\hline 4. & NOVEL & 157 & 281 & 560.7 & 553.488 \\
\hline
\end{tabular}

A comparison is drawn between the performance of proposed leach with LEACH, LEACH C, LEACH CC Protocol in terms of network lifetime and in terms of FND, HND.Performance. Comparison results for network lifetime of proposed leach with that Leach,leach c,leach cc protocol shown in figure 6.The network lifetime of proposed algorithm has improved further from other existing protocols. Proposed algorithm improves the network life time by $84.69 \%$ 
International Journal of Peer to Peer Networks (IJP2P) Vol.5, No.3, August 2014

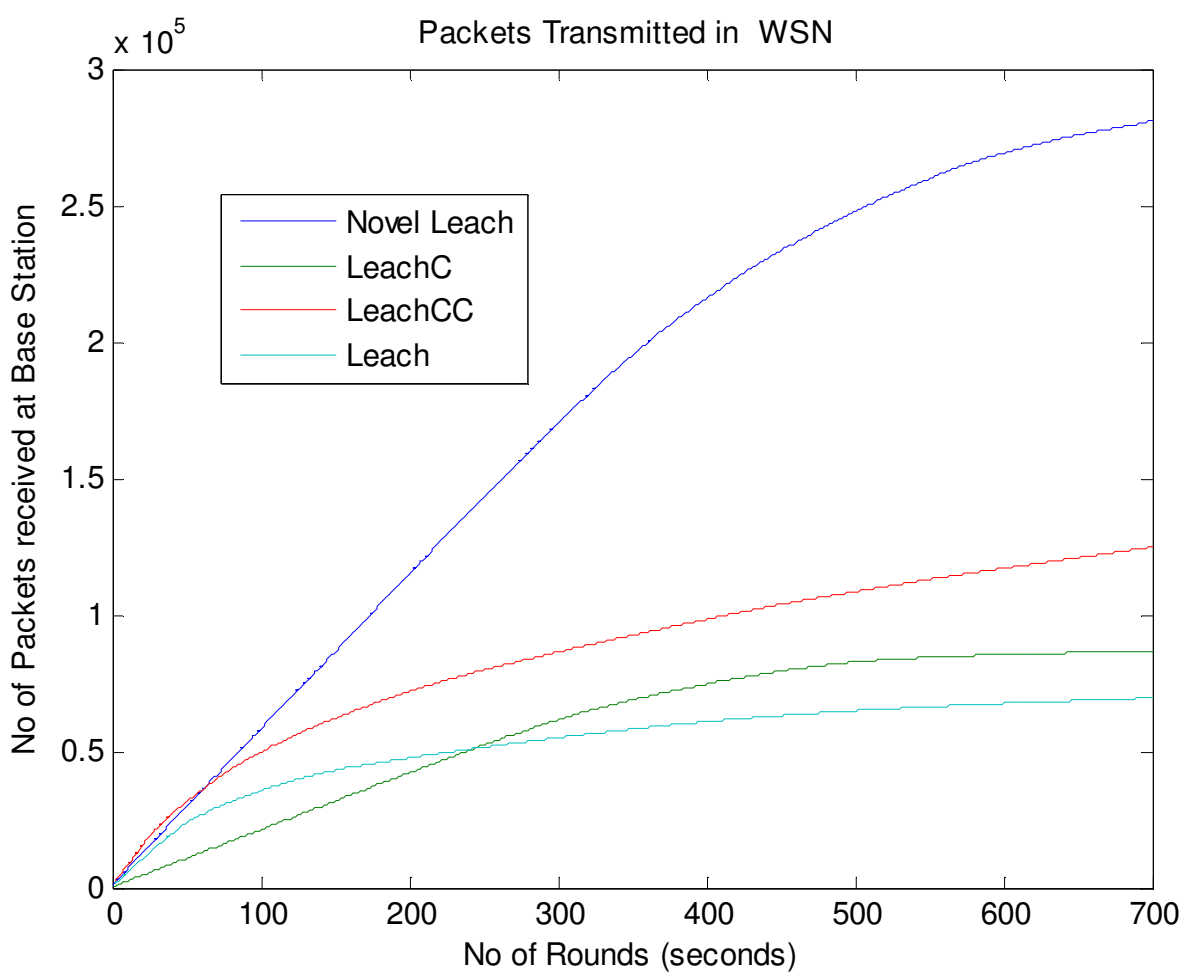

Figure 7. Comparative analysis of packets transmitted to BS

Table 4 PACKET TRANSMITTED TO BS

\begin{tabular}{|l|l|l|}
\hline SNO & ALGORITHM & PACKETS SEND TO BS \\
\hline 1. & LEACH & 69,100 \\
\hline 2. & LEACH C & 82,200 \\
\hline s3. & LEACH CC & $1,24,736$ \\
\hline 4. & NOVEL & $2,83,076$ \\
\hline
\end{tabular}

The comparative analysis of packets transmitted to Base Station shows that proposed algorithm transmit more data packets to Base Station.The comparative analysis of Novel leach is done with Leach, leach c, leach cc respectively. 
International Journal of Peer to Peer Networks (IJP2P) Vol.5, No.3, August 2014

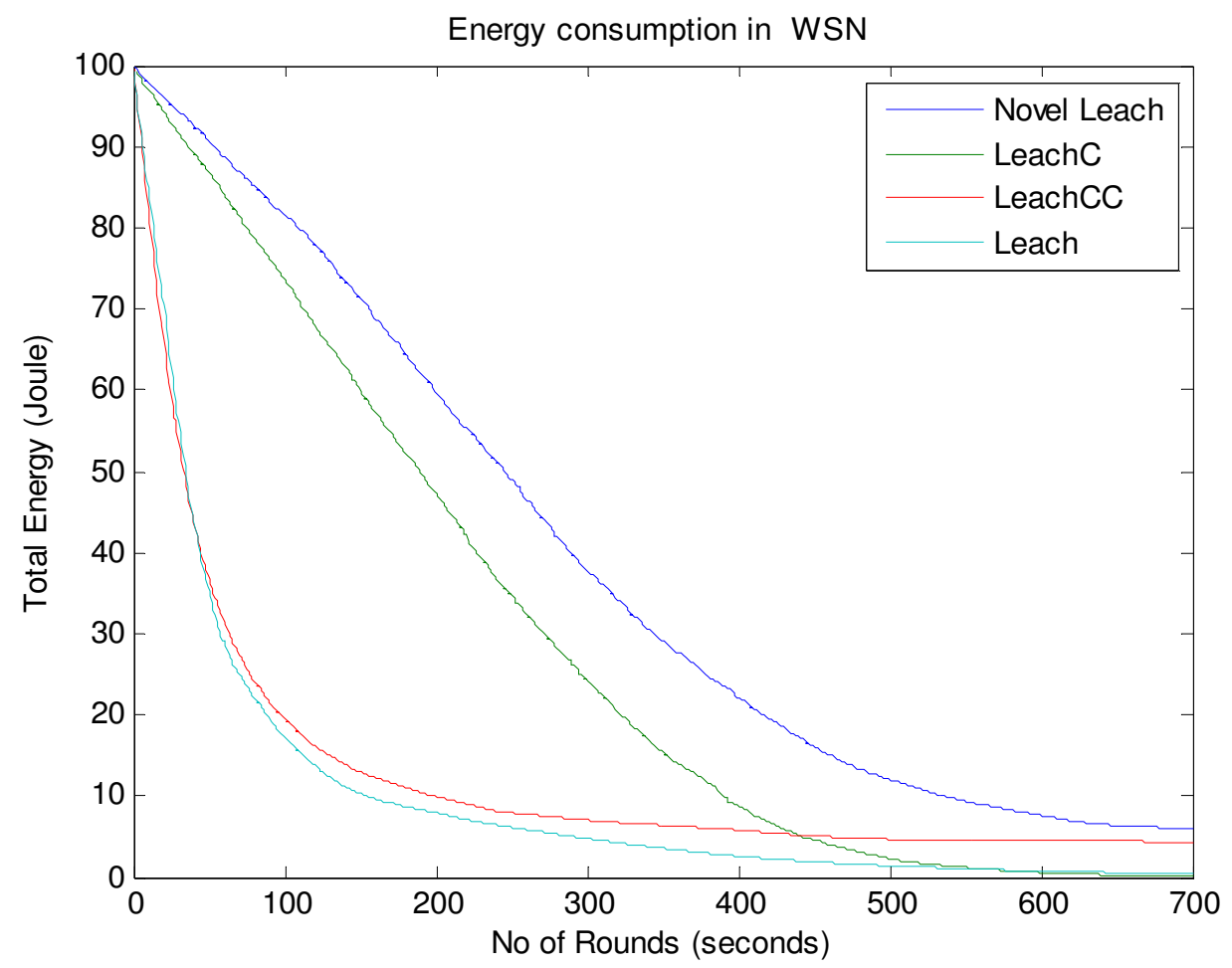

Figure 8.Comparative analysis of Energy Consumption

Table 5 Energy Consumption Results at 700 rounds

\begin{tabular}{|l|l|l|}
\hline S no & Protocol Name & Total energy remaining \\
\hline 1. & LEACH & 0.3587 joule/second \\
\hline 2. & LEACH C & 0.7938 joule/second \\
\hline 3. & LEACH CC & 3.8920 joule/second \\
\hline 4. & NOVEL LEACH & 8.2194 joule/second \\
\hline
\end{tabular}

The comparative analysis of energy consumption in the sensor network. Leach has very less remaining energy as compare to Novel LEACH. Novel Leach consume less energy as compare to Leach c,leach cc.

\section{CONCLUSION}

To increase Network life time is a challenging issue in WSN .In our proposed protocol, We use two parameter energy, distance to Base Station for cluster head selection. The proposed 
International Journal of Peer to Peer Networks (IJP2P) Vol.5, No.3, August 2014

algorithm results conclude that it is better than Leach, Leach $\mathrm{C}$, and Leach CC. It prolongs network life time by $84 \%$ and less energy consumption as compare to basic LEACH.

\section{REFERENCES}

[1] Adrian Perrig , John Stankovic and David Wagner," Security in wireless sensor network",. Vol. 47, pp.6-9 ,June 2004.

[2] Bolian Yin, Hongchi Shi, and Yi Shang ,"Analysis of Energy Consumption in Clustered Wireless sensor Networks" IEEE Transactions on Mobile Computing, vol. 3, pp. 272-285, July 2007

[3] Curt Schurgers and Mani B. Srivastava "Energy efficient routing in Wireless Sensor Networks", IEEE Personal Communications Mag., Vol.7, No.5, pp.16-27, Oct. 2000

[4] Fan Xiangning and Song Yulin, "Improvement on LEACH Protocol of Wireless Sensor Network", IEEE Communications Magazine,, 40(8), pp.102-114, Mar.2002.

[5] Hiren Kumar Deva Sarma and Avijit Kar, "Security Threats in Wireless Sensor Networks" IEEE Communications Magazine, 42(4): 122-134, August 2002.

[6] Ioan Raicu ,’Routing Algorithms for Wireless Sensor Networks", IEEE Wireless Communications, vol.46, pp.110-119,Sept.2002.

[7] Jan Steffan ,Ludger Fiege, Mariano Cilia and Alejandro Buchmann, "Scoping in Wireless Sensor Networks", IEEE Network, 18(1), pp.15-21, May 2004.

[8] John Buckley, Kevin Aherne and Cian O'Mathuna, "Antenna Performance Measurements Using Wireless Sensor Networks", Proceedings of the IEEE, VOL. 91, pp. 1247-1256, August 2003.

[9] Kay Romer and Friedemann Mattern, Eth Zurich,"The design space of wireless sensor network", CACM, vol. 43, pp. 74-82,Mar. 2000.

[10] Kun Zhang and Cong Wang, "A Secure Routing Protocol for Cluster-Based Wireless Sensor Networks Using Group Key Management,” IEEE Xplore,vol.37, pp. 178-185, jan.-2008.

[11] L.Li, and J.Y. Halpern, "Minimum-Energy Mobile Wireless Networks Revisited,", IEEE International Conference on Communications (ICC). Vol. 1, pp. 278-283, 2001.

[12] L. Subramanian and R. H. Katz "An Architecture for Building Self Configurable Systems", in the Proceedings of IEEE/ACM Workshop on Mobile Ad Hoc Networking and Computing, Boston, MA, August 2000.

[13] M. Ibrahim Channa and Irum Memon, "Real Time Traffic Support in Wireless Sensor Networks" IEEE Comm. Magazine, pp.119-133, June 2001.

[14] Mihaela Cardei , Jie Wu and Mohammad O. Pervaiz,"Maximum Network Lifetime in Wireless Sensor Networks with Adjustable Sensing Ranges", IEEE Communications Magazine, pp 102-114, Aug.2002.

[15] Peng-Jun Wan, Member and Chih-Wei Yi, "Coverage by Randomly Deployed Wireless Sensor Networks", IEEE Wireless Communications and Networking Conference, pp.16-20, Mar. 2003.

[16] Q. Li and J. Aslam and D. Rus, "HPAR: Hierarchical Power-aware Routing in Sensor Networks", In Proceedings of the DIMACS Workshop on Pervasive Networking, May, 2001.

[17] Qi YAO, Seng- Kee TAN, Yu GE, Boon-Sain YEO and Qinghe YIN, "An Area Localization Scheme for Large W ireless Sensor Networks” MOBICOM, pp269- 286, July 2001.

[18] Sang-Sik Kim and Ae-Soon Park, "Mobility Support for Users in Wireless Sensor Networks", IEEE Communications Magazine, vol. 40, pp.124-156 Aug. 2002

[19] Shafiq Hashmi and Hussien T. Moufth, "A New Transport Layer Sensor network protocol”, IEEE Transactions, vol. 5,pp.118-156,Mar.2003

[20] Shangwei Duan and Xiaobu Yuan, "Exploring Hierarchy Architecture for Wireless Sensor Networks Management", IEEE Communications Magazine, 40(8), pp.102-114, Aug. 2002.

[21] Rogaia Mhemed et al.,"An Energy Efficient Fuzzy Logic Cluster Formation Protocol in wireless Sensor Networks," The 3rd International Conference on Ambient Systems, Networks and Technologies,Niagara Falls, Ontario, Canada. 27-29 August 2012. http://nrl.northumbria.ac.uk/7042/ 


\section{Authors}

Harpreet Kaur is the mtech student in Department of Electronics and Communication Engineering, Guru Nanak Dev Engineering College Ludhiana. She has published several research papers in wireless communication .Her area of research interest is Wireless communication systems.

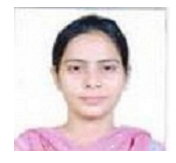

Prof. Ameeta Seehra is presently working as associate professor in Department of Electronics and communication engineering , Guru Nanak Dev Engineering college ,Ludhiana. She has received her B.E. in Electronics and Comm. engg in 1986 and M.Tech. Electronics and Comm. engg in 1997.She has guided more than 20 students for Mtech Thesis .She is a member of ISTE. Her area of research interest is advanced communications. 